\title{
Acta Botanica Mexicana, hacia una revista electrónica de alta calidad
}

\author{
Marie-Stéphanie Samain \\ Editor responsable
}

Desde su primera presentación por el Instituto de Ecología, A.C. (INECOL) en abril de 1988, Acta Botanica Mexicana ha publicado periódicamente y sin interrupción 116 números con artículos originales sobre temas botánicos. La versión impresa ha sido enviada a instituciones de casi 50 países en todo el mundo y su contenido está disponible gratuitamente en Internet desde el año 2006. Cuenta con un factor de impacto en el Science Citation Index desde 2009 y es ampliamente indexada en bases de datos de revistas internacionales, latinoamericanas y mexicanas.

Con el presente número de Acta Botanica Mexicana lanzamos un nuevo formato de nuestra revista de Acceso Abierto, incluyendo la aplicación gradual de nuevas instrucciones para autores, la presentación de los títulos de artículos en español e inglés, las fechas de recepción, las de la decisión editorial basadas en los comentarios de revisores, y de aceptación en la primera página del manuscrito, resúmenes estructurados, inclusión de identificadores digitales de objetos (DOI por sus siglas en inglés), así como una presentación más moderna y homogénea de los contenidos del artículo. Desde el mes de septiembre 2016, también hemos comenzado a utilizar la plataforma de gestión y publicación Open Journal Systems (OJS), a consultar en http://abm.ojs.inecol.mx, con el fin de profesionalizar y acelerar nuestra gestión editorial.

Estas y otras novedades que pueden consultar en nuestra página web son requeridas por el Consejo Nacional de Ciencia y Tecnología (CONACYT) y siguen las directrices internacionales para revistas científicas de alta calidad, mientras que otras, como las instrucciones detalladas destinadas a guiar a los autores a través del proceso de preparación y envío de sus manuscritos, se introducen para simplificar los esfuerzos de los autores, revisores y editores con la ayuda de reglas claras. A partir del próximo número (enero de 2017), utilizaremos únicamente la plataforma OJS para publicar la revista, entre otros para reducir a cero los costos de impresión y los gastos de envío. Este proceso nos permitirá enfocarnos más en la personalización y optimización de la página web, ya que ahora usamos el formato estándar de OJS desarrollado por el Public Knowledge Project.

Recordamos a los taxónomos que el Artículo 29.1 del Código Internacional de Nomenclatura para algas, fungi y plantas ("Código de Melbourne") afirma que la publicación de nuevos nombres a partir del 1 de enero 2012 también se efectúa mediante la distribución de material electrónico en formato de documento portátil (PDF por sus siglas en inglés) en una publicación electrónica con un Número Internacional Normalizado de Publicaciones Seriadas (ISSN por sus siglas en inglés) o un Número Internacional Normalizado del Libro (ISBN por sus siglas en inglés). Estamos tramitando actualmente el número ISSN para la versión electrónica de Acta Botanica Mexicana, por lo que podremos garantizar la publicación efectiva de los nombres de los nuevos taxones a partir del siguiente número.

Los temas cubiertos por nuestra revista serán esencialmente los mismos que antes. Seguimos aceptando manuscritos de alta calidad sobre cualquier tema relacionado con la botánica y la ecología de plantas en el sentido más amplio, esencialmente sobre las plantas y los hongos mexicanos, pero también consideramos manuscritos de otras áreas geográficas. Por supuesto, damos la bienvenida a contribuciones taxonómicas y florísticas, independientemente de su tamaño. Aparte de este tipo de estudios más tradicionales, también invitamos a los autores a enviar manuscritos sobre estudios moleculares, tales como reconstrucciones filogenéticas, filogeografía, genética de poblaciones, genética ecológica y genómica.

La publicación de taxones nuevos para la ciencia seguirá siendo un enfoque importante y de ahora en adelante vamos a publicar estos artículos fast track, por supuesto, solo cuando pasen con éxito el proceso de revisión. Todas las demás contribuciones (excepto obituarios y reseñas de libros) serán tratadas y publicadas en el orden de aceptación. Sin embargo, a medida que so- 
licitamos a los revisores enviar sus comentarios en el plazo de tres semanas, esperamos reducir considerablemente el tiempo entre fecha de recepción y la primera decisión editorial para todo tipo de contribuciones.

Durante 28 años, nuestro editor fundador Jerzy Rzedowski sirvió incansablemente como Editor responsable, logrando junto con su equipo el reconocimiento internacional para Acta Botanica Mexicana. Él me designó como Co-editor en abril de 2013, lo que me dio la oportunidad de familiarizarme con el estilo de trabajo y las particularidades de la revista hasta que fui nombrada Editor responsable en mayo 2016 por el Director General del INECOL, Martín Ramón Aluja Schuneman Hofer, dado que Jerzy Rzedowski había renunciado inesperadamente poco antes y la mayoría de sus editores asociados también habían dejado el equipo editorial. Estoy especialmente agradecida por el apoyo incondicional de las autoridades del INECOL, así como la de nuestros asistentes editoriales y nuestros editores asociados, por lo que pudimos salvaguardar la revista y su futuro. El presente equipo sigue la filosofía de Jerzy Rzedowski, ahora nuestro Editor Honorario, mediante el apoyo a los autores para publicar sus manuscritos para satisfacer la creciente necesidad de publicar en revistas indexadas en el Science Citation Index.

Esta revista continúa siendo editada en el Centro Regional del Bajío del INECOL, ubicado en Pátzcuaro, Michoacán, México, que tiene como principal misión generar, transferir y comunicar conocimiento científico sobre la taxonomía, sistemática, filogenia, ecología, diversidad y conservación de la flora mexicana. Nos sentimos muy privilegiados de poder editar esta revista prestigiosa en el marco de nuestra misión, más aún porque nos encontramos en el corazón de una de las zonas con mayor biodiversidad de nuestro planeta. Sin embargo, debido a las severas presiones antropogénicas, muchas especies en los hotspots de biodiversidad en esta región están seriamente amenazadas y podrían extinguirse, incluso antes de que hayamos sido capaces de descubrir y describirlas, o entender su desarrollo, evolución, relaciones, dispersión o sus ecosistemas. Acta Botanica Mexicana refleja la riqueza de las disciplinas de investigación en las que se estudia esta biodiversidad y esto también se ejemplifica en el presente número.

Sirviendo a la comunidad botánica en México y en el extranjero, de este modo esperamos dar la bienvenida a un grupo cada vez mayor de autores, revisores, editores y lectores. 